\title{
O outro lado da moeda na autoria textual coletiva: o perfil dos construtores da Wikipédia *
}

\author{
Luiz Alexandre da Silva Rosado - Mestre em Educação, UNESA \\ alexandre.rosado@globo.com
}

\section{Resumo}

A Wikipédia, enciclopédia aberta e editada pelos próprios usuários, se tornou um dos fenômenos recentes na internet e chama atenção pelo vasto número de verbetes e áreas do saber que abrange. Dessa forma surge o questionamento sobre qual seria o perfil dos chamados wikipedistas, aqueles que usam ou editam os conteúdos da "enciclopédia livre". Podemos classificar a Wikipédia como comunidade virtual, um espaço on-line que materializa através dos seus textos a inteligência coletiva. Ela nem sempre é harmônica, apresentando conflitos e instabilidades, com algumas centenas de usuários mais dedicados e ativos, sendo a grande maioria usuários eventuais ou editores esporádicos. Os wikipedistas são de classe média, entre 20 e 40 anos de idade, cursando graduação ou especialização, com grande conhecimento em informática e se entusiasmam frente às possibilidades de compartilhamento coletivo de saberes. Terminamos o artigo com algumas reflexões para futuros estudos a respeito da relação entre a academia e os autores de discursos textuais extra-institucionais, acessados por inúmeros estudantes em diferentes níveis de ensino.

Palavras-chave: autoria textual coletiva; comunidades virtuais; perfil dos wikipedistas.

\section{The other side of the coin in collective text authorship: the Wikipedia constructors profile.}

\begin{abstract}
The Wikipedia, an open encyclopedia edited by users, became a recent internet phenomena and directs person's attention about the vast number of entries and sections of knowledge it embraces. So that arises doubts about the profile of wikipedians, those who use or edit contents on the "free encyclopedia". We can classify Wikipedia as a virtual community, an on-line place that materializes among their texts the collective intelligence. It's not always harmonic, showing conflicts and instabilities, with some hundreds of users more dedicated and active, being a greater number occasional users or sporadic editors. The majority of wikipedians are middle-class, between 20 and 40 years old, studying in undergraduate courses or college specializations, with a vast instruction in informatics and great enthusiasm about the possibilities of collective knowledge sharing. We conclude this paper with some reflections for future studies about the relationship between academy and extrainstitutional textual discourses authors, accessed by many students from different levels of instruction.
\end{abstract}

Keywords: collective text authorship; virtual communities; wikipedian's profile.

\footnotetext{
* Este artigo conta com resultados extraídos da dissertação "Autoria textual coletiva fora do âmbito acadêmico e institucional: análise da comunidade virtual Wikipédia e suas contribuições para a Educação". A realização do mestrado contou com bolsa PROSUP concedida pela CAPES entre os anos de 2006 e 2008. O conteúdo foi atualizado a partir do artigo "Autoria textual coletiva fora do âmbito acadêmico e institucional: delineando o perfil dos wikipedistas" apresentado durante o $1^{\circ}$ Colóquio de Educação e Mídia, UNIRIO, 2007. V. 6 № 1 , Julho, 2008
} 


\section{Introdução}

Pierre Lévy (1996) há mais de uma década antecipava os rumos da internet ao descrever as possibilidades de autoria conjunta (coletiva) de textos a partir da colaboração de inúmeros internautas. Hoje a tecnologia que permite essa autoria já está consolidada. Porém a pergunta que se faz com mais freqüência é sobre quem está por trás de tais construções coletivas e qual a qualidade dos textos construídos nessas novas bases de dados compartilhadas.

Partindo de tais questionamentos e procurando-se estudar um caso específico e significativo, o objetivo deste artigo é delinear, levando-se em consideração os conceitos de inteligência coletiva e comunidade virtual (Lévy, 1998; 1999), o perfil do usuário e/ou editor da enciclopédia on-line Wikipédia, denominado neste artigo de wikipedista. A partir da formação deste quadro poderemos entender melhor os rumos da autoria coletiva de textos quando baseada em tecnologias que permitem a colaboração on-line.

$\mathrm{Na}$ Wikipédia existe uma forma de escrita que possibilita a autoria coletiva de textos, usualmente chamada de wiki. Isso quer dizer que há uma opção para que qualquer internauta interfira e crie o conteúdo dos textos disponibilizados no site, com exceção de algumas páginas protegidas pelos administradores do sistema. Estes artigos/verbetes estão em constante crescimento e são classificados em inúmeras categorias que abrangem grande parte das áreas do conhecimento humano (biologia, geografia, história, medicina, etc).

A extrema maleabilidade ${ }^{1}$ dos textos da Wikipédia leva-nos a questionar os modos tradicionais de autoria de textos de caráter teórico e científico como aqueles produzidos para enciclopédias e revistas científicas impressas, organizados por equipes de especialistas, com edições periódicas e que legitimam principalmente os discursos daqueles que possuem grau universitário avançado através do sistema de revisão pelos pares (peer review) (Targino, 2003). A escrita antes da codificação digital estava condicionada pela publicação analógica em papel, porém o texto digitalizado e compartilhado em rede passou a oferecer novas possibilidades de intervenção e editoração para serem exploradas, e tudo indica que estamos somente no início dessa nova fase (Targino, 2005).

Dessa forma surge a necessidade de se entender quem está construindo a Wikipédia, enciclopédia iniciada em junho de 2001 em sua versão em língua portuguesa, e quais são, caso existam, suas relações com a autoria científica e universitária tradicionais. Tal comparativo se faz necessário, pois a autoria textual teórica da universidade é o paradigma de qualidade e confiabilidade para os textos que são construídos a partir dessas pesquisas publicadas como, por exemplo, os textos didáticos, as enciclopédias e os livros científicos.

\section{A Web 2.0 e o internauta interventor ativo}

Até uma década e meia atrás (anos 1990), quando pensávamos em enciclopédia pensávamos nos volumes numerados e dispostos em ordem alfabética em nossa estante. Porém de alguns anos para cá surgiu a Wikipédia, site que ultrapassa em dezenas de vezes o número de verbetes presentes em enciclopédias tradicionais como a Britannica, Larousse e Barsa. Enquanto a Wikipédia alcança hoje mais de 5 milhões de verbetes (somadas todas as línguas), raramente as enciclopédias impressas chegam na casa de 100 mil entradas.

Podemos enumerar alguns fatores de ordem técnica que permitiram o surgimento da Wikipédia $^{2}$. O primeiro deles foi a configuração do que se denominou microinformática, nos anos 1970-80, com a minituriarização dos componentes eletrônicos que permitiram o 
advento do computador pessoal (PC). Nesse período as interfaces gráficas popularizaram o acesso aos computadores, mais baratos e mais fáceis de operar.

Após essa fase, o PC pouco a pouco se integra às redes de computadores e torna-se conectado. André Lemos (2002, p. 112) denominou esse computador de CC, o computador conectado. Essa conexão física entre os computadores, através de cabos e modems, permitiu a partir da metade dos anos 80 o compartilhamento de memórias entre os PCs. Dados analógicos convertidos em dados digitais (fenômeno da digitalização) passaram a ser modulados e demodulados entre as máquinas. A internet se tornou a rede mais popular entre as existentes, surgindo diversas aplicações para aproveitar os potenciais desse novo meio de comunicação, sendo uma delas a World Wide Web por volta do ano de 1991.

No início a internet possuía inúmeras páginas estáticas, ou seja, entrávamos em um site e observávamos seu conteúdo, líamos os textos e apreciávamos, em alguns casos, imagens e vídeos disponibilizados, e só. Porém pouco a pouco passamos de usuários espectadores a internautas interventores ativos.

O modelo de internet chamado Web 2.0 (Fortes, 2006) ou Internet Rica nada mais representa que o aproveitamento da bidirecionalidade permitida pelas comunicações online, o modelo de comunicação denominado de todos-todos por Lévy (1999), ou seja, a possibilidade de se manipular e transferir dados digitais em mão dupla e com todos os internautas que participam do ambiente. Quanto ao binômio emissor-receptor, para Lemos (2002, p. 114) “o ciberespaço fez com que qualquer um possa não só ser consumidor, mas também produtor de informação, emissor". Essa mesclagem de papéis, representada nas palavras de Lemos como liberação do pólo de emissão vai marcar a cibercultura, ou seja, a cultura contemporânea permeada pelas tecnologias digitais.

A internet, em sua estrutura sem centros e sem periferias, estabelece o fim da restrição técnica que impossibilitava interferência em um ambiente de comunicação, característica visível no século XX marcado pelo rádio, pela TV e pelo cinema analógicos e pela definição de espectador. Na visão de Lévy (2001, p. 42), "toda história das mídias atua no desencadeamento da colaboração das consciências". Isso quer dizer que o mundo vem apresentando um crescente estado de interconexão até chegarmos na Era Digital e na formação do ciberespaço, um espaço-não-espaço onde as memórias e ações humanas são registradas e compartilhadas em tempo real, formando a inteligência coletiva digitalizada.

\section{Autoria coletiva na web: novos espaços de legitimação dos saberes}

São justamente esses saberes entrelaçados no ciberespaço e seus modos de produção de autoria que devem interessar aos educadores, a partir da utilização dos sistemas wiki para incentivar a autoria coletiva entre seus alunos, fazendo as adaptações ${ }^{3}$ necessárias para o contexto educativo (Lund \& Smørdal, 2006). Nesse novo cenário, ou estágio de comunicação onde, em tese, todos podem participar da construção das mensagens, a Wikipédia surgiu como uma das possibilidades para aproveitar o potencial dos sistemas wiki e ser um espaço coletivo de compartilhamento de saberes.

Isso não quer dizer que a própria internet não apresentaria a função de compartilhamento de saberes, porém uma página de internet com espaço para a catalogação do saber humano aberto a qualquer pessoa, com expressiva produção textual em tão curto espaço de tempo, se torna um fenômeno que vale a pena ser observado. A princípio teria tudo para fracassar e ser um espaço de confusão e desorganização que tenderia ao desaparecimento ou descaso, porém ocorreu justamente o contrário. A ausência de poder 
central controlador não gerou a desordem, mas sim uma espécie de autogoverno através da criação de regras e normas de convivência e conduta por seus próprios usuários.

A Wikipédia foi criada com a proposta de se tornar uma enciclopédia escrita por seus próprios usuários. Isso quer dizer que o usuário pode, a princípio, transferir para o site os saberes próprios, em que ele é especialista, e compartilhar com os outros internautas interessados, desde que obedeça as regras de estilo e grafia disponíveis no site da enciclopédia, assim como as recomendações sobre direitos autorais. Como o critério passa a ser a qualidade do texto em si, ocorre uma desvinculação entre a autoria e as credenciais, tais como os diplomas e outros tipos de certificações formais. $\mathrm{O}$ wikipedista desta forma indica através de suas contribuições os talentos, as competências e os conhecimentos muitas vezes não reconhecidos oficialmente (Lévy, 1999, p. 177-183).

A Wikipédia dessa forma interferiu na cadeia lógica até então aceita para a produção de saberes enciclopédicos, ou seja, nas enciclopédias tradicionais são os especialistas selecionados e reconhecidos academicamente que são convidados a escrever um verbete que passa por rigorosa revisão antes de ser posto na enciclopédia. Na Wikipédia o verbete está em aberto, podendo ser modificado a qualquer momento (inclusive por especialistas), em permanente e movediço estado de construção e destruição.

O simples, ao mesmo tempo complexo, fato de um verbete estar aberto para a edição por seus visitantes abre inúmeras questões, principalmente aquelas ligadas à legitimidade ou confiabilidade do texto que está sendo exposto. Nos tópicos seguintes procuraremos elucidar o perfil dos wikipedistas para entender melhor quem são esses editores, e de que forma eles lidam com a instabilidade que a Wikipédia possui ao utilizar de maneira radical uma das principais características dos dados digitais: a maleabilidade.

\section{Metodologia da pesquisa}

A coleta de dados, realizou-se através de três fontes de informações. A primeira fonte foi um questionário contendo 67 itens divididos em 7 blocos temáticos, disponibilizado na internet através do programa gratuito (open source) gerador de questionários chamado PHPSurveyor 1.0. A segunda fonte foi a observação de conversas entre wikipedistas na sala de bate-papo \#wikipedia-pt, através do programa mIRC 6.21. A terceira fonte de dados foram as conversas mantidas com wikipedistas através do programa de mensagens instantâneas Windows Live Messenger 8.1. Uma fonte importante dentro da própria Wikipédia são as informações do Portal Comunitário, incluindo regras e acordos da comunidade virtual assim como as discussões textuais travadas entre os membros.

O questionário, após sua concepção e ajustes adicionais, foi disponibilizado na

própria internet. A razão desta decisão deve-se ao fato dos sujeitos da pesquisa usarem obrigatoriamente a internet para acesso ou edição de verbetes na Wikipédia, não prejudicando desta forma a amostragem, pois a totalidade dos wikipedistas tem acesso à rede de computadores. Os temas dos 7 blocos foram: 1. Dados básicos sobre você; 2 . Seu conhecimento de informática; 3. Wikipédia em geral; 4. Wikipédia e seu conteúdo; 5. Wikipédia e confiabilidade; 6. Comunicações com wikipedistas; 7. Uso de recursos da Wikipédia. A abordagem individual direta no perfil dos wikipedistas revelou-se a maneira mais eficaz para se coletar os dados.

A segunda fonte de informações, o canal de bate-papo \#wikipedia-pt, permitiu um acesso às conversas mais espontâneas entre os wikipedistas, abrangendo inúmeros assuntos que muitas vezes não podem ser explorados nas páginas da Wikipédia e nem nas respostas 
dos questionários, em geral redigida de maneira mais formal. Após a criação de um apelido este pesquisador ficou registrando por alguns dias não consecutivos as conversas entre os wikipedistas para posterior análise.

A terceira fonte de informações, as conversas ocorridas via instant messenger, contou com alguns wikipedistas que na função de administradores disponibilizaram seus endereços para contatos e puderam intermediar ou auxiliar nas abordagens deste pesquisador com os wikipedistas em geral. O caráter mais privado representado pela conversa individual permitiu a realização de entrevistas particulares tanto com usuários avançados como iniciantes na utilização da Wikipédia.

\section{Um perfil estatístico do wikipedistas ${ }^{4}$}

No encerramento deste trabalho foram recebidas 159 respostas ao questionário disponibilizado on-line, entre os dias 14 de maio e 26 de agosto de 2007. A primeira constatação é que os respondentes possuem um vínculo já estabelecido e forte com a Wikipédia (veteranos), e se propuseram a dedicar um tempo mais longo para responder ao questionário. Isso é indicado pelo percentual deles que já editaram e contribuíram com os verbetes no site: $93,7 \%$.

Quanto à faixa etária a grande maioria indicou ser jovem e solteiro, com 77,4\% (123 respondentes) situando-se entre 16 e 40 anos de idade, e do sexo masculino com 88,7\% do total. Entre as mulheres destaca-se proporcionalmente a faixa etária dos 26 aos 60 anos de idade distribuída com certo equilíbrio quantitativo. Curiosamente, nenhum respondente tinha mais de 60 anos de idade.

A maioria indicou sua localidade nas regiões Sul e Sudeste do Brasil com quase 40\% residindo nas cidades do Rio de Janeiro e São Paulo. Porém houve 26 respondentes de Portugal continental mais 1 respondente de Açores, 2 da Espanha, 1 da Alemanha, 1 da Bélgica, 1 da Irlanda, 1 da Suécia, 1 do Reino Unido, 1 da Argentina e 1 da China (Macau).

Quanto à renda, a maioria se identificou como classe média, sendo 42,4\% classe média baixa e 48,6\% classe média alta. Esse percentual evidencia a relação entre inclusão digital (acesso ao computador e à internet) e a renda pessoal ou familiar. Essa percepção de pertencimento a uma classe social foi importante fator no estudo, pois como grande parte dos respondentes são jovens, muitas vezes sem renda própria e dependentes dos familiares, uma simples declaração de remuneração pessoal daria a falsa impressão de que a intervenção na Wikipédia ocorre significativamente em classes sociais baixas.

No item escolaridade houve maior concentração de respostas entre o ensino médio incompleto e a graduação completa $(70,3 \%)$, o que corresponde ao perfil jovem de classe média já indicado acima. Porém 22\% declararam já possuírem ou estarem cursando especialização ou estarem cursando ou concluído o mestrado. Entre os doutores e aqueles que estão cursando o pós-doutorado o índice foi de somente 3,8\%. Percebe-se no geral que o nível de escolaridade do grupo de wikipedistas respondentes é alto, porém está longe de um perfil tipicamente acadêmico.

A grande maioria, 83,6\%, nunca publicou um artigo em revista científica. Isso explica o fato da grande maioria utilizar como fonte de pesquisa as páginas da própria internet $(81,8 \%)$ e depois os livros impressos $(71,7 \%)$, um hábito menos frequiente no meio acadêmico que recorre mais às pesquisas publicadas em revistas científicas e a resultados de teses, dissertações e fontes primárias de dados. Somente $37,7 \%$ dos respondentes 
declararam utilizar revistas científicas para elaborarem os verbetes da Wikipédia, já dicionários $(48,4 \%)$ e enciclopédias $(62,3 \%)$ são bastante utilizados.

No momento de elaborar as referências bibliográficas, as normas da $\mathrm{ABNT}^{5}$ são adotadas por somente $42,6 \%$ dos 92 respondentes que marcaram esta questão, e 11,9\% deles declararam desconhecimento sobre a existência de tais normas. Como as normas ABNT são brasileiras, entre os brasileiros esse percentual se eleva para 49,4\% entre os que a adotam, porém o desconhecimento das normas se mantém em igual patamar, contrastando-se com os portugueses mais conhecedores de normas para referências bibliográficas.

Quanto ao domínio de línguas estrangeiras, metade dos 159 respondentes declararam já ter contribuído escrevendo verbetes em outras Wikipédias, sendo a grande maioria $(54,7 \%)$ em língua inglesa, seguidos pelos idiomas espanhol $(27,7 \%)$ e francês $(18,2 \%)$.

A confiabilidade nos conteúdos da Wikipédia é positiva a partir do fato de que boa parte dos respondentes já utilizaram seus conteúdos como fonte de pesquisa em trabalhos escolares $(32,7 \%)$, de faculdade $(25,8 \%)$ e profissionais $(33,3 \%)$. Porém quando se referem à pesquisa acadêmica somente $18,2 \%$ indicaram a utilização de artigos da Wikipédia como fonte para suas pesquisas, se devendo talvez ao baixo número de acadêmicos respondentes.

A confiança depositada no site pode ser vista quando se constata que para $96,9 \%$ dos respondentes a Wikipédia pode ajudar os estudantes em seu processo de aprendizagem, principalmente como fonte de informações complementares que servem de ponto de partida para outras fontes, por ser abrangente em seus temas, fácil de ser compreendida em seus textos e poder ser acessada pela internet de modo gratuito. Outros motivos estão relacionados a atributos da própria estrutura digital do site, tais como atualização permanente e estrutura hipertextual que estimula a busca de temas correlatos. O aprendizado pelo exercício da escrita coletiva foi citado por poucos.

Quando ao acesso à informática, destacou-se o fato de 64,8\% dos respondentes já estarem utilizando microcomputadores antes do ano de 1995 e somente 5,7\% terem se declarado usuários iniciantes. Já quanto à internet a maioria declarou ter iniciado seus acessos entre os anos de 1995 e 2000 . Estes dados indicam que os usuários mais afins com a Wikipédia possuem alto grau de familiaridade com a informática. No tempo de acesso à Wikipédia a maioria pode ser considerada novata, pois $83,3 \%$ dos respondentes declararam ter começado a utilizar o site entre os anos 2004 e 2006 (ele foi criado em 2001).

Quanto à comunicação, 78,6\% afirmaram que interagem com outros wikipedistas, principalmente dentro da própria Wikipédia nas abas de discussão dos verbetes $(59,7 \%) \mathrm{e}$ nas abas de discussão dentro do perfil dos wikipedistas (63,5\%). Outras duas formas de comunicação que se destacaram foram a por e-mail $(28,3 \%)$ e por instant messengers (30,2\%). A título de curiosidade $11,3 \%$ dos respondentes afirmaram se encontrar presencialmente, um número talvez bem alto para uma comunidade virtual dispersa geograficamente, porém não muito surpreendente quando se percebe que a maioria se encontra próxima em grandes centros urbanos.

\subsection{Além das utopias: uma inteligência coletiva nem sempre harmônica}

Em seu livro Cibercultura, Pierre Lévy considera 3 princípios que orientam o crescimento do ciberespaço (p.127-132): a interconexão (interligação das máquinas no 
ciberespaço), as comunidades virtuais (interligação das pessoas no ciberespaço) e a inteligência coletiva (interligação dos conhecimentos no ciberespaço).

Curiosamente, Lévy fazendo um paralelo com as comunidades on-line existentes atualmente, declara que "a comunidade científica é a primeira comunidade virtual, a primeira comunidade que se organizou numa inteligência coletiva, sobre uma base independente das barreiras nacionais e religiosas" (2001, p. 78). Tal fato resultou do aproveitamento de duas estruturas de comunicação que floresceram no século XVI: a da imprensa e da rede postal (correios) que se estabeleceram nesse período. Essa primeira comunidade virtual, tal como a Wikipédia, baseou-se na troca de saberes e conhecimentos, mas hoje se vê desafiada pelas comunidades fundadas sob outro suporte: o suporte digital, maleável e em tempo real da internet.

A Wikipédia pode ser considerada também uma comunidade, só que on-line, sem um espaço territorial físico, que opera no ciberespaço e "é construída sobre as afinidades de interesses, de conhecimentos, sobre projetos mútuos, em um processo de cooperação ou de troca, tudo isso independentemente das proximidades geográficas e das filiações institucionais" (Lévy, 1999, p. 127, grifo nosso).

Quanto aos interesses e intenções, percebe-se na fala dos wikipedistas respondentes algumas concepções sobre a Wikipédia compartilhadas e que os motiva a participar ativamente, sendo as respostas a seguir referentes à Questão $\mathrm{n}^{\circ} 26$ "Em primeiro lugar, como você definiria a Wikipédia? O que ela significa para você?": "unificação de todo conhecimento humano"(Respondente n⿳8), "experiência única de conhecimento na História humana"(Respondente $\mathrm{n}^{\circ}$ 9), "repositório unificado de todo conhecimento livre" e "uma utopia"(Respondente $\left.n^{\circ} 12\right)$, "projetos mais louváveis da humanidade"(Entrevista $\mathrm{n}^{\circ} 3$ ).

A vontade de participar de uma comunidade que almeja distribuir o conhecimento humano em sua totalidade para toda humanidade conectada é a utopia motivadora de muitos wikipedistas. Está em sintonia com o otimismo de Lévy que ao falar sobre o conceito de inteligência coletiva afirma que "essa nova dimensão da comunicação deveria, é claro, permitir-nos compartilhar nossos conhecimentos e apontá-los uns para os outros, o que é a condição elementar da inteligência coletiva" (1998, p. 17-18, grifo nosso).

A inteligência coletiva ultrapassaria as coletividades humanas e seus conhecimentos locais transmitidos de maneira oral ou pela escrita impressa, pois no ciberespaço esse saber compartilhado estaria sendo alimentado e acessado por todos através da conectividade, modificado a todo instante a partir da intervenção daqueles que estão interligados de maneira hipertextual, permanentemente indexado e atualizado.

Apesar de tais declarações, em termos práticos a Wikipédia, tal como a comunidade científica, não se constitui um ambiente em permanente harmonia, com todos convivendo sem conflitos. Para Lévy (1999, p. 128) "longe de serem frias, as relações on-line não excluem as emoções fortes", e é isso que verificaremos nas análises dos dados coletados entre os wikipedistas, como por exemplo, a ponderação feita por um dos respondentes e o desabafo de ordem política feito pelo outro:

\section{Questão 26 - Respondente $n^{\circ} 17$}

(...) a Wikipedia, assim como qualquer outro ambiente Wiki tem muitas falhas. O conhecimento é incompleto e muitas vezes pouco confiável. Informações corretas são vandalizadas e assuntos sensíveis como política ou religião têm que ser mantidos sob estreita vigilância (...) Muitos usuários não entendem que a Wikipédia é um projeto com um objetivo específico e gastam tempo excessivo 
em aspectos secundários (...) Como em qualquer grupo humano é preciso administrar egos e formas diferentes de pensar e agir.

Questão 26 - Respondente no 6

A wikipedia em português é um campo de guerra político onde uma elite minoritária de egos inflados se digladiam em busca de atenção e reconhecimento (...), enquanto uma maioria alheia contribui com amplo conhecimento de modismos e futilidades inócuas (...) belo reflexo da comunidade lusófona (...).

A primeira declaração revela claramente um problema comum compartilhado pelos wikipedistas: os atos de vandalismo. São ações realizadas por usuários que desejam destruir ou embaralhar os conteúdos dos artigos, inserindo informações de origem duvidosa ou intencionalmente falsas. A extrema maleabilidade da Wikipédia possui um preço e esse preço é conviver a todo momento com atos de vandalismo e destruição. Semelhante a uma cidade aberta e democrática, onde o direito de ir e vir está garantido, mas que vez por outra ocorrem assaltos, depredações e toda sorte de atos vandálicos, a Wikipédia também possui seus "policiais" voluntários que vigiam e restauram os conteúdos daqueles verbetes que foram alterados de maneira maliciosa, contando com a ajuda de softwares que monitoram

alterações consideradas suspeitas. É uma espécie de guerra invisível para manter a coesão e a organização da Wikipédia.

Na declaração do Respondente $\mathrm{n}^{\circ} 17$ se observam outras facetas do vandalismo que ultrapassam a simples destruição: são as disputas ideológicas ou as guerras de idéias. Estas disputas estão relacionadas, como destaca o usuário, a temas sensíveis como posições de ordem política e de ordem religiosa. O desabafo do Respondente $n^{\circ} 6$ mostra que essa guerra acaba deixando certo ressentimento entre os wikipedistas.

\subsection{Muitos acessam, porém poucos contribuem}

Uma das visões mais interessantes que se forma sobre a Wikipédia é a de que pelo fato de ser livre, podendo ser alterada por quem a acessa, ela recebe contribuições de milhares de pessoas, de maneira difusa e sem, a princípio, personalidades definidas ${ }^{6}$. Porém percebe-se, em uma análise mais detalhista, que a troca e cooperação na comunidade virtual nem sempre ocorre de maneira uniforme, ou seja, com a mesma proporção de engajamento e investimento de tempo dos participantes.

$\mathrm{Na}$ Wikipédia, segundo a página wikistats $^{7}$ em língua portuguesa, existiam, em setembro de 2007, 9947 usuários registrados. Desse total, 1659 (16,68\%) foram classificados como ativos, ou seja, contribuíram 5 ou mais vezes durante o mês e 221 contribuiram 100 ou mais vezes $(2,22 \%)$. Quanto ao número absoluto de edições, 306 wikipedistas $(3,07 \%)$, segundo estatísticas fornecidas no Portal Comunitário da Wikipédia ${ }^{8}$ referentes a dezembro de 2007, possuíam mais de 2000 edições realizadas. A contagem de edições inclui qualquer tipo de alteração realizada em verbetes da Wikipédia, incluindo as abas "Artigo" e "Discussão", não importando o volume de texto inserido ou a qualidade do conteúdo. Quando se percebe que em dezembro de 2007 a Wikipédia estava chegando na casa dos 350 mil verbetes, pode-se questionar até que ponto a intervenção na enciclopédia não se restringe a pequeno número de interessados muito dedicados ao projeto.

$\mathrm{Na}$ hierarquia da Wikipédia existem os administradores e os burocratas, que possuem alguns privilégios dentro da comunidade virtual, sendo que as candidaturas e as eleições ocorrem periodicamente. Quando se analisa a listagem de wikipedistas e o número de edições torna-se claro que os administradores e os burocratas são aqueles que se 
encontram entre os maiores editores da enciclopédia. Em janeiro de 2008 eram 78 administradores e 5 burocratas de um total de 306 wikipedistas com mais de 2000 edições $(27,1 \%)$.

Nesta mesma listagem, antes da tabela com os apelidos e os respectivos totais de edições, existe um aviso de que a listagem não representa uma competição por quem possui maior número de edições e nem deve ser interpretada como tal. Porém pode-se perceber que um maior número de edições não deixa de representar critério no momento que se deseja avaliar a importância de um wikipedista.

Na seção Esplanada:anúncios, onde foi inserido o pedido para que os wikipedistas respondessem ao questionário desta pesquisa houve o comentário de uma wikipedista que surpreendeu-se com a qualidade do questionário já que este autor tinha 3 anos de registro na Wikipédia e havia realizado somente 44 edições em artigos. Dessa forma percebe-se que o conhecimento quanto ao funcionamento da Wikipédia para essa wikipedista está ligado ao total de intervenções que se realiza nela, ou seja, o número de edições é um dos fatores que aumenta a confiabilidade e a reputação do wikipedista junto aos seus pares.

Durante a observação no mIRC, um outro fator que chamou atenção foi a existência de pequeno número de usuários presentes no canal de bate-papo \#wikipedia-pt, mas que permaneceram conectados por longos períodos. Ou seja, há pouca rotatividade no canal de bate-papo oficial, onde praticamente todos se conhecem e o acessam freqüentemente. Esse fato aponta para a existência de pequeno percentual de wikipedistas mais fiéis, vigilantes e que se vincularam de maneira forte ao projeto da Wikipédia.

\section{Conclusões}

Como foi esclarecido no início deste artigo, não se pretendia esgotar o tema ou traçar um perfil definitivo do wikipedista, até porque esta tarefa se torna quase impossível, visto que o número de usuários e suas formas de utilização deste espaço virtual modificamse a todo instante, característica típica dos sites da chamada Web 2.0. Porém algumas tendências puderam ser delineadas e são estas que revisaremos a seguir.

Podemos resumir alguns pontos fortes tratados neste artigo que desfazem algumas idéias que a princípio pode-se construir a respeito da Wikipédia. A primeira idéia é a de que por ser uma enciclopédia livre, ela necessariamente deve ser harmônica (idealização). Para refutar esta concepção, foi demonstrado que são frequientes os atos de vandalismo e destruição de verbetes, sendo criados para isso uma série de mecanismos de vigilância e punição, muitas vezes geridos por sofisticados softwares de análise que auxiliam os wikipedistas mais engajados em manter a ordem e a correção dos textos do site.

A segunda idéia é a de que por estar disponível e aberta na internet a Wikipédia é editada por milhares de pessoas de maneira difusa e uniforme. Tal visão é refutada a partir do momento que se constata a existência de pequena minoria que se dedica de forma extrema à manutenção e escrita de conteúdos na enciclopédia, cerca de 300 wikipedistas.

Quanto ao perfil destes wikipedistas ativos, percebe-se que são usuários em sua maioria homens e jovens, cursando graduação e alguns já com especialização e mestrado, de classe média e com acesso facilitado à internet, possuindo grande familiaridade com a informática. Em grande parte são entusiastas dedicados a compilar áreas específicas do conhecimento que possuem maior afinidade, sem necessariamente serem pesquisadores, mestres ou doutores interessados em produzir ou expor descobertas inéditas. 
Algumas reflexões podem ser propostas a partir dos dados coletados. Em primeiro lugar, surge a questão da pouca participação dos pesquisadores acadêmicos na construção dos textos da Wikipédia sugerida pelos resultados do questionário. Como hipótese pode-se eleger dois fatores básicos para esta ausência: o primeiro seria que a partir da maleabilidade extrema da Wikipédia, um texto construído com perícia e profundidade poderia ser alterado para pior por qualquer wikipedista ao acessar e editar o verbete, fato este que não acontece em um texto publicado em revista científica.

Um segundo fator seria a impossibilidade do pesquisador listar sua contribuição na Wikipédia como publicação válida, por exemplo, em seu currículo Lattes ou em outros mecanismos indexadores de pesquisas semelhantes existentes em outros países (o texto não é de sua propriedade, é coletivo). A única motivação que sobraria para contribuir seria o retorno simbólico da satisfação em contribuir compartilhando seus conhecimentos e saberes, o que não parece bastar, a princípio, para estes pesquisadores acadêmicos que precisam muitas vezes manter um ritmo alto de publicações anuais em revistas científicas já consagradas para manter seus cargos e benefícios de trabalho (Targino, 2003, 2005).

Em segundo lugar, face às repercussões encontradas na mídia e na convivência com colegas no meio acadêmico, surge a questão: porque a Wikipédia incomodaria acadêmicos e professores a ponto de alguns deles censurarem a utilização do site como fonte de consulta em trabalhos escolares?

Um primeiro fator poderia ser o questionamento da confiabilidade dos textos disponíveis no site, que podem conter (e muitos contém de fato) erros grosseiros de conteúdo, informações incompletas e imprecisões como já foi apontado por inúmeras matérias na mídia (Costa, 2007). Porém a indicação de checagem em outras fontes de referência seria mais indicada que a simples censura, abordando-se a Wikipédia como fonte inicial de consulta.

Um segundo fator, que levanto como hipótese, seria o fato de que a Wikipédia se tornou um site acessado e visto como fonte confiável para os internautas, em especial os estudantes. Esse voto de confiança dado por seus usuários-leitores a uma fonte construída coletivamente por internautas, fora da academia, pode gerar desconfiança por parte de acadêmicos e professores, argumento este válido quando percebemos que a maioria dos wikipedistas não costumam escrever textos em formato acadêmico, sem consultar livros e revistas científicas, e muitos ainda estão no ensino médio ou cursando faculdade.

Essas duas questões apontam a necessidade de estudos futuros que esclareçam com precisão a relação entre academia e os autores de discursos textuais extra-institucionais hoje representados, por exemplo, pelos wikipedistas, acessados por inúmeros estudantes em diferentes níveis de ensino. Vale refletir que o suporte exclusivamente impresso predominante antes da Era Digital geraram uma demanda reprimida de pessoas que agora expressam sua autoria (com a liberação do pólo de emissão), antes impossibilitada ou mesmo negada. Esses autores não estão vinculados a uma estrutura institucional oficial e legitimadora representada pela universidade, escolas ou centros de pesquisa, criando regras de legitimação próprias (controles de qualidade), mas não desvinculadas totalmente do modelo acadêmico como se percebe ao se analisar algumas posturas, como a necessidade de se inserir referências bibliográficas, aplicar a norma culta da língua e buscarem a imparcialidade dos conteúdos.

\section{Notas}

V. 6 № 1 , Julho, 2008 
${ }^{1}$ O termo maleável e maleabilidade será utilizado neste trabalho para designar o caráter de simulação, transformação e rearranjo permitido pelos bits, uma das características mais marcantes do formato digital que permite o surgimento de diferentes expressões do pensamento e da imaginação, potencialidade esta amplificada quando os dados digitais passam a ser compartilhados na internet.

${ }^{2}$ Para um maior detalhamento deste processo evolutivo das tecnologias digitais ver o capítulo II "A infraestrutura técnica do virtual" no livro Cibercultura (LÉVY, 1999, p. 31-44).

${ }^{3}$ Embora muitas adaptações sejam necessárias para facilitar a cooperação e colaboração dos estudantes em sistemas wiki, algumas sugestões podem tender ao controle e vigilância excessivos por parte dos professores, que correm o risco de se tornarem agentes inibidores da criatividade e da espontaneidade necessárias às trocas e aprendizagem entre os alunos.

${ }^{4}$ Os percentuais foram arredondados, com no máximo 1 casa decimal, evitando-se a presença de muitas casas decimais, consideradas menos relevantes para a formação do perfil básico dos wikipedistas. Os percentuais foram calculados pelo software Sphinx 4.5, utilizado também para a análise de conteúdo das respostas discursivas.

${ }^{5}$ Este número baixo para uso das normas ABNT reflete a resposta negativa dos respondentes portugueses que possuem outras convenções bibliográficas em seu país representadas pelo Instituto Português de Qualidade (IPQ). Esse fato não foi levado em consideração na elaboração do questionário (omissão do pesquisador por desconhecimento).

${ }^{6}$ Quando o usuário se registra no site ela passa a ser identificado em suas alterações, a partir do apelido escolhido no momento do registro. Esse apelido muitas vezes é o nome real do wikipedista. Também em muitos casos o wikipedista se identifica através de sua página pessoal na Wikipédia.

${ }^{7}$ Disponível em: http://stats.wikimedia.org/PT/Sitemap.htm

${ }^{8}$ Disponível em http://pt.wikipedia.org/wiki/Wikipedia:Lista_de_wikipedistas_por_n\%C3\%BAmero_de_edi\%C3\%A7\%C3\% B5es

\section{Referências bibliográficas}

CARDILLI, J. Anônimos impulsionam internet colaborativa. G1. 09 fev. 2007. Disponível em: <http://g1.globo.com/Noticias/0,,MUI5032-6174,00.html>. Acesso em 01 mar. 2007.

COSTA, A. L. M. C. da. Referência fast-food. Carta Capital, São Paulo. n. 431, fev. 2007. Disponível em: <http://www.cartacapital.com.br/2007/02/ referencia-fast-food/>. Acesso em 01 jul. 2007.

FORTES, D. Web 2.0. InfoExame, São Paulo, SP, n. 243, p. 44-49, jun. 2006.

LEMOS, A. Aspectos da cibercultura - vida social nas redes telemáticas. In: PRADO, J. L.

A. Crítica das práticas midiáticas: da sociedade de massa às ciberculturas. São Paulo, SP: Hacker Editores, 2002. 168 p.

LÉVY, P. A conexão planetária: o mercado, o ciberespaço, a consciência. Tradução Maria Lúcia Homem e Ronaldo Entler. São Paulo, SP: Editora 34, 2001. 192 p. Tradução de: World Philosophie.

LÉVY, P. A inteligência coletiva: por uma antropologia do ciberespaço. Tradução Luiz Paulo Rouanet. 4. Ed. São Paulo, SP: Edições Loyola, 1998. 216 p. Tradução de: L'intelligence collective. Pour une antropologie de cyberspace.

LÉVY, P. Cibercultura. Tradução Carlos Irineu da Costa. São Paulo, SP: Editora 34, 1999. 264 p. (Coleção TRANS). Tradução de: Cyberculture. 
LÉVY, P. O que é o virtual? Tradução Paulo Neves. São Paulo, SP: Editora 34, 1996. 160 p. (Coleção TRANS). Tradução de: Qu'est-ce que le virtuel?

LUND, A.; SMØRDAL, O. Is there a space for the teacher in a WIKI? In:

INTERNATIONAL SYMPOSIUM ON WIKIS, 2., 2006, Odense, Dinamarca. Anais. ACM Press, 2006.

TARGINO, M. G. Novas tecnologias e produção científica, uma relação de causa e efeito ou uma relação de muitos efeitos? In: CONGRESSO BRASILEIRO DE CIÊNCIAS DA COMUNICAÇÃO, 26., set. 2003, Belo Horizonte, MG. Anais. São Paulo: Intercom, 2003. (CD-ROM).

TARGINO, M. G. Artigos científicos: a saga da autoria e co-autoria. In: CONGRESSO BRASILEIRO DE CIẾNCIAS DA COMUNICAÇÃO, 28., 2005, Rio de Janeiro, RJ. Anais. São Paulo: Intercom, 2005. (CD-ROM). 